\title{
Tribunais de Contas Brasileiros são transparentes?*
}

\author{
¿Son transparentes los Tribunales de Cuentas brasileños? \\ Are the Brazilian Courts of Accounts transparent?
}

Clea Beatriz Macagnan ${ }^{\text {a }}$

Universidade do Vale do Rio dos Sinos, UNISINOS, Brasil

DOI: https://doi.org/10.11144/Javeriana.cc20-50.tcbt

cleabeatrizm@gmail.com

ORCID: http://orcid.org/0000-0002-9097-7266

Recepção: 20 Fevereiro 2019

Rodrigo Vargas Laureano

Aprovação: 28 Agosto 2019

Faculdade de Integração do Ensino Superior do Cone Sul,

Brasil

ORCID: http://orcid.org/0000-0001-9141-3916

Victorino Piccinini Rosso

Universidade de Passo Fundo, UPF, Brasil

ORCID: http://orcid.org/0000-0002-7929-4149

Daniel Wartchow

Universidade de Santa Cruz do Sul, UNISC, Brasil

ORCID: http://orcid.org/0000-0003-1773-8397

\section{Resumo:}

Esta pesquisa analisa o grau de transparência dos Tribunais de Contas brasileiros, considerando a disponibilidade dos seus relatórios de atividades nas respectivas páginas eletrônicas na Internet e seu conteúdo. As evidências indicam que 26,5\% dos relatórios de atividades não estavam disponibilizados, no período analisado, nas páginas eletrônicas dos Tribunais de Contas brasileiros, indicando a existência de problemas de transparência e/ou de tempestividade na divulgação de tais informações. Em relação aos relatórios disponibilizados, realizou-se a análise de conteúdo e foi observada a ausência de padronização dos mesmos, o que traz prejuízos à comparabilidade entre as informações divulgadas pelos Tribunais de Contas. Os resultados desta pesquisa evidenciam que os Tribunais de Contas brasileiros, em seu conjunto, não cumprem adequadamente a recomendação do sistema de Governança Pública, na medida em que deixam de informar sobre o seu comportamento e as atividades desenvolvidas. Esse cenário leva a inferir a necessidade que têm os Tribunais de Contas brasileiros de aprimoramento de transparência e accountability de acordo com as práticas recomendadas de governança pública.

Códigos JEL: D53, M14, O16.

Palavras-chave: governança pública, tribunais de contas, transparência.

\section{Resumen:}

Esta investigación analiza el grado de transparencia de los Tribunales de Cuentas brasileños, considerando la disponibilidad de sus informes de actividades en las respectivas páginas web y su contenido. Las evidencias indican que el $26,5 \%$ de los informes de actividades no estaban disponibles, en el periodo analizado, en las páginas web de los Tribunales de Cuentas brasileños, indicando la existencia de problemas de transparencia y/o de divulgación oportuna de dicha información. En relación a los informes disponibles, se realizó el análisis de contenido y se observó la ausencia de estandarización de los mismos, lo que perjudica la comparabilidad entre las informaciones divulgadas por los Tribunales de Cuentas. Los resultados de esta investigación evidencian que los Tribunales de Cuentas brasileños, en su conjunto, no cumplen adecuadamente la recomendación del sistema de Buen Gobierno Público, en la medida en que dejan de informar sobre su comportamiento y las actividades desarrolladas. Este escenario lleva a inferir la necesidad que tienen los Tribunales de Cuentas brasileños de mejorar transparencia y accountability de acuerdo con las prácticas recomendadas de Buen Gobierno.

Códigos JEL: D53, M14, O16.

Palabras clave: gobernanza pública, tribunales de cuentas, transparencia.

\section{Autor notes:}




\begin{abstract}
:
This research analyzes the degree of transparency of the Brazilian Courts of Accounts, considering the availability of their activity reports on the respective websites and their content. The evidence indicates that $26.5 \%$ of the activity reports were not available, in the period analyzed, on the websites of the Brazilian Courts of Accounts, indicating the existence of problems of transparency and/or timely disclosure of such information. Regarding the available reports, the content analysis was performed and the lack of standardization of them was observed; this impairs the comparability between the information disclosed by the Courts of Accounts. The findings of this research show that the Brazilian Courts of Accounts, as a whole, do not adequately comply with the recommendation of the public governance system, insofar as they cease to report on their behavior and the activities carried out. This leads to infer the need of the Brazilian Courts of Accounts to improve transparency and accountability in accordance with the recommended practices of Public Governance.
\end{abstract}

JEL Codes: D53, M14, O16.

Keywords: Public Governance, Courts of Accounts, Transparency.

\title{
INTRODUÇÃO
}

Transparência e accountability são aspectos essenciais no que se refere à Governança Pública (IFAC, 2001; ONU, 2007). A primeira capaz de possibilitar que a sociedade pressione o governo para que ofereça os serviços necessários e o faça corretamente. A segunda, ao estabelecer critérios de avaliação de desempenho das instituições públicas, contribui para o incremento da legitimidade de um governo (ONU, 2007). Neste contexto estão inseridos os Tribunais de Contas, órgãos aos quais foi atribuída a responsabilidade pelo controle financeiro externo sobre a Administração Pública (Brasil, 1988; Arantes et al., 2010).

O referido controle é exercido mediante mecanismos previstos na Constituição Federal, ou em outros dispositivos legais, como é o caso da Lei de Responsabilidade Fiscal -LRF-, sancionada em 04 de maio de 2000, cujo projeto foi apresentado ao Congresso Nacional pela Presidência da República em abril de 1999. A LRF conferiu aos Tribunais de Contas o papel de seu guardião, bem como definiu importantes aspectos relativos à transparência das informações da Administração Pública (Brasil, 2000; Arantes et al., 2010). Mesmo com tais responsabilidades, os Tribunais de Contas brasileiros, de uma forma geral, podem estar sujeitos aos problemas de tempestividade e de uniformidade na disponibilização das informações referidos no Manual de Transparência Fiscal (FMI, 2007).

Os mencionados problemas podem ocorrer em razão da legislação que trata dos relatórios de atividades dos Tribunais de Contas brasileiros. As Constituições Federal e Estadual, além das Leis Orgânicas Municipais, exigem a apresentação de relatórios das atividades dos respectivos Tribunais de Contas ao Poder Legislativo. No entanto, tal obrigatoriedade não define expressamente como deverá ser a divulgação dos relatórios, o prazo para sua elaboração e apresentação ou, ainda, o conteúdo das informações que devem ser apresentadas neles.

Considerando o contexto apresentado, a presente pesquisa teve por objetivo identificar se os Tribunais de Contas brasileiros disponibilizam os seus relatórios de atividades nas respectivas páginas eletrônicas na Internet para depois comparar os disponibilizados. Com essa finalidade estes foram analisados em seu conteúdo, classificando os assuntos tratados e apontando semelhanças e diferenças entre as formas de apresentação das informações dos órgãos de controle acima mencionados.

A população da pesquisa corresponde aos Tribunais de Contas brasileiros existentes no encerramento do exercício de 2016. Esse número corresponde ao Tribunal de Contas da União -TCU-, aos 26 Tribunais de Contas dos Estados -TCE-, ao Tribunal de Contas do Distrito Federal -TCDF-, aos dois Tribunais de Contas de Municípios -TCM- e aos quatro Tribunais de Contas dos Municípios -TCM-, o que totaliza 34 Tribunais de Contas. Vale destacar que estas organizações representam $100 \%$ da população, sendo que as despesas orçamentárias previstas para o exercício de 2018 totalizaram R \$ 10,7 bilhões. Desse total não fazem parte da amostra nove Tribunais de Contas, cujos relatórios de atividades do exercício de 2016 não se encontravam disponibilizados nas respectivas páginas eletrônicas no período da pesquisa. Assim, a amostra diz respeito aos vinte e cinco relatórios de atividades obtidos mediante consulta das páginas eletrônicas dos 
referidos órgãos. Tal amostra representa $73,5 \%$ da população pesquisada, permitindo a análise conjunta do conteúdo dos relatórios disponibilizados. Em relação aos relatórios não disponibilizados, a amostra possibilita a discussão quanto à transparência das ações dos Tribunais de Contas brasileiros.

A Lei de Responsabilidade Fiscal ensejou a temática relacionada à transparência na Administração Pública no Brasil, a qual vem sendo objeto de atenção da sociedade e dos órgãos de controle. Destaca-se, inclusive, a edição de normativos legais que tratam do tema, como: a Lei da Transparência (Lei Complementar $n^{\circ}$ 131/2009), a Lei de Acesso à Informação (Lei Federal no 12.527/2011) e o Decreto no 9.203/2017, por exemplo. Este último trata da política de governança da administração pública federal. No entanto, é restrito o número de estudos empíricos que abordam a transparência no âmbito da Administração Pública, no que tange aos Tribunais de Contas. E em relação aos Tribunais de Contas, estudos nacionais abordam a diversidade entre os órgãos regionais (Lino e Aquino, 2018), ou então, o funcionamento e os seus mecanismos de interação social (Fernandes, Fernandes e Teixeira, 2018), não avançando quanto ao aspecto da transparência dos relatórios de atividades de tais órgãos. Neste sentido, espera-se que o presente artigo possa contribuir para preencher a lacuna relativa a estudos empíricos que tratem da temática da transparência no âmbito dos Tribunais de Contas brasileiros, assim como promover discussão no sentido de que movimentos podem ser estabelecidos com vistas a melhorar o sistema de governança pública.

Na próxima seção é abordada a temática relacionada à Governança Pública e a sua relação com os Tribunais de Contas e os relatórios de atividades. A terçã seção trata de estudos empíricos relacionados ao tema, enquanto a seção quarta apresenta a metodologia aplicada. Na seção quinta faz-se a apresentação dos resultados e a seção sexta traz as considerações finais do estudo.

\section{GOVERNANÇA PÚBLICA: TRIBUNAIS DE CONTAS E SEUS RELATÓRIOS DE ATIVIDADES}

Governança Pública configura-se por um sistema de regras utilizado para garantir a legitimidade e a efetividade na utilização dos recursos públicos (Kooiman, 1999). Em sentido semelhante, Osborne (2006) entende que a Governança Pública enfatiza o controle, a gestão e a auditoria de desempenho e, com isto, amplia o profissionalismo das ações em detrimento ao viés político das decisóes. Já o Decreto n 9.203/2017 (artigo $2^{\circ}$, inciso I) define Governança Pública como mecanismo de liderança, estratégia e controle que avalia, direciona e monitora a gestão pública para que os serviços prestados atendam aos interesses da sociedade (BRASIL, 2017). Ao estabelecer um comparativo entre a Governança Pública e a Nova Administração Pública, Peters e Pierre (1998) dizem que ambas se assemelham no que diz respeito à minimização do papel e da importância dos eleitos, a qual se restringe à definição das metas e das prioridades.

O Study 13 desenvolvido pela International Federation of Accountants - IFAC (2001) menciona a existência de três princípios fundamentais de Governança Corporativa, os quais também são aplicáveis ao setor público: 1) integridade, referida à probidade e à eficiência na administração dos recursos públicos; 2) accountability, relacionada ao processo pelo qual os governantes e os indivíduos que gerenciam recursos públicos são responsáveis por suas ações e decisões e possuem a obrigação de submeter-se ao escrutínio externo; e 3) transparência, caracterizada pela divulgação de informações completas, claras e precisas sobre as ações e as decisões tomadas pelos agentes públicos, bem como a possibilidade de consulta e de questionamentos em relação a tais ações e decisões (IFAC, 2001).

De acordo com a Organização das Nações Unidas (ONU, 2007), accountability e transparência estariam diretamente ligados. A accountability incluiria a definição de critérios para avaliar o desempenho das instituições públicas, contribuindo assim para o incremento da legitimidade de um governo. Já a transparência faz com que os governos liberem o fluxo de informações ao público e com isto proporcionem uma participação ativa no sentido de garantir que a informação pública tenha um efeito de feedback sobre o desempenho do 
governo. Tal perspectiva visa permitir que a sociedade pressione o governo a fornecer os serviços necessários e faça-o corretamente (ONU, 2007).

O’Donnell (1998), ao estabelecer a distinção entre accountability vertical e accountability horizontal, destacou que a primeira está relacionada às ações individuais ou coletivas realizadas em relação àqueles indivíduos que ocupam posições superiores no Estado. Já a existência de órgãos que possuam o poder legal, o poder de fato e a capacidade de fiscalizar e de punir os agentes e as agências do Estado, que tenham atuado de forma ilegal, caracteriza o que O'Donnell (1998) definiu como accountability horizontal. No Brasil, o Ministério Público e os Tribunais de Contas são exemplos de órgãos responsáveis pela accountability horizontal (Arantes et al., 2010). Ao primeiro compete a defesa da ordem jurídica, do regime democrático e dos interesses sociais e individuais indisponíveis, enquanto que aos Tribunais de Contas foi atribuído o exercício do controle financeiro externo sobre a Administração Pública (Brasil, 1988).

O referido controle externo é exercido mediante diversos mecanismos, entre estes, a emissão de parecer prévio relativo às contas prestadas pelos chefes do poder executivo, o julgamento das contas daqueles que administram recursos públicos, a realização de auditorias e de inspeções e a apreciação da legalidade dos atos de admissão de pessoal, entre outros procedimentos (incisos I a XI, artigo 71, Constituição Federal, 1988). Além de tais atribuições, a Lei de Responsabilidade Fiscal (Brasil, 2000; Arantes et al., 2010) conferiu aos Tribunais de Contas o papel de seu guardião, o que inclui a fiscalização quanto aos gastos de pessoal, à existência de desequilíbrio das contas públicas e à transparência das informações relativas à Administração Pública (Brasil, 2009).

No encerramento do exercício de 2016, no Brasil existiam trinta e quatro Tribunais de Contas: o Tribunal de Contas da União (TCU); vinte e seis Tribunais de Contas dos Estados (TCE); o Tribunal de Contas do Distrito Federal (TCDF); dois Tribunais de Contas de Município e quatro Tribunais de Contas dos Municípios (Speck, 2000; Melo et al., 2009). Destes, o Tribunal de Contas dos Municípios do Ceará (TCMCE) foi extinto[1] em 2017. A diferença entre os Tribunais de Contas refere-se à jurisdição de cada um, conforme apresentado na tabela 1 .

TABELA 1

Jurisdição dos Tribunais de Contas brasileiros existentes em 2016

\begin{tabular}{lclll}
\hline Denominação & Quantidade & Órgão & Jurisdição & $\begin{array}{l}\text { A quem presta } \\
\text { auxilio }\end{array}$ \\
\hline $\begin{array}{l}\text { Tribunal de contas } \\
\text { da união (TCU) }\end{array}$ & 01 & Federal & União & $\begin{array}{l}\text { Congresso } \\
\text { Nacional }\end{array}$ \\
$\begin{array}{l}\text { Tribunal de Contas } \\
\text { dos Estados (TCE) }\end{array}$ & 26 & Estadual & $\begin{array}{l}\text { Estados e Municipios nos } \\
\text { Estados da Federação que } \\
\text { não possuem Tribunal de } \\
\text { Contas dos Municípios. }\end{array}$ & $\begin{array}{l}\text { Assembleias } \\
\text { Legislativas. } \\
\text { Câmaras } \\
\text { Municipais. }\end{array}$ \\
$\begin{array}{l}\text { Tribunal de Contas } \\
\text { do Distrito Federal } \\
\text { (TCDF) }\end{array}$ & 01 & Distrital & Distrito Federal & Câmara Legislativa \\
$\begin{array}{l}\text { Tribunal de Contas } \\
\text { do Município } \\
\text { (TCM) }\end{array}$ & 02 & Municipal & $\begin{array}{l}\text { Municípios de São Paulo e } \\
\text { do Rio de Janeiro }\end{array}$ & $\begin{array}{l}\text { Câmaras } \\
\text { Municipais }\end{array}$ \\
$\begin{array}{l}\text { Tribunal de Contas } \\
\text { dos Municípios } \\
\text { (TCM) }\end{array}$ & 04 & Estadual & $\begin{array}{l}\text { Todos os Municípios dos } \\
\text { Estados da Bahia, Goiás, } \\
\text { Pará e Ceará }\end{array}$ & $\begin{array}{l}\text { Câmaras } \\
\text { Municipais }\end{array}$ \\
\hline
\end{tabular}

elaborado pelos autores, a partir de Simões (2014)

Os artigos 71 a 75 da Constituição Federal do Brasil de 1988 estabelecem o regramento geral e as atribuições do Tribunal de Contas da União, sendo que tais regras e atribuições, por simetria, também são estendidos aos demais Tribunais (artigo 75, Constituição Federal, 1988). Nestas cláusulas exige-se que os Tribunais de Contas apresentem, trimestral e anualmente, o relatório de suas atividades ao respectivo Poder Legislativo ( $\$ 4^{\circ}$, do artigo 71 , combinado com o artigo 75 , ambos da Constituição Federal de 1988). Além da 
exigência da Constituição Federal, tal apresentação está contemplada nas Constituições Estaduais e nas Leis Orgânicas dos Municípios, conforme excertos apresentados, a título de exemplo, na tabela 2.

TABELA 2

Relatórios de atividades nas Constituições Estaduais

\begin{tabular}{|c|c|c|}
\hline $\begin{array}{l}\text { UF da } \\
\text { Constituição }\end{array}$ & $\begin{array}{l}\text { Artigos, } \\
\text { Parágrafos e } \\
\text { Incisos } \\
\end{array}$ & Texto da Constituição \\
\hline Acre & Art. $61, \S 4^{\circ}$ & $\begin{array}{l}\text { O Tribunal de Contas do Estado encaminhará à Assembleia } \\
\text { Legislativa, trimestral e anualmente, relatório de suas } \\
\text { atividades e a esta prestará contas, na forma da lei. }\end{array}$ \\
\hline Bahia & Art. $91, \S^{\circ}$ & $\begin{array}{l}\text { Os Tribunais prestarão suas próprias contas à Assembleia } \\
\text { Legislativa, bem como a ela encaminharão, trimestral e } \\
\text { anualmente, relatório de suas atividades. }\end{array}$ \\
\hline Goiás & Art. $26, \S 4^{\circ}$ & $\begin{array}{l}\text { O Tribunal encaminhará à Assembleia Legislativa, trimestral } \\
\text { e anualmente, relatório de suas atividades. }\end{array}$ \\
\hline Santa Catarina & Art. $59, \S 4^{\circ}$ & $\begin{array}{l}\text { O Tribunal encaminhará à Assembleia Legislativa, trimestral } \\
\text { e anualmente, relatório de suas atividades. }\end{array}$ \\
\hline São Paulo & Art. $33, \S^{\circ}$ & $\begin{array}{l}\text { O Tribunal encaminhará à Assembleia Legislativa, trimestral } \\
\text { e anualmente, relatório de suas atividades. }\end{array}$ \\
\hline
\end{tabular}

Elaborado pelos autores, a partir de consulta às respectivas Constituições Estaduais do Acre (1989), Bahia (1989), Goiás (1989), Santa Catarina (1989), São Paulo

(1989).

Como se observa, a exigência restringe-se à apresentação dos relatórios de atividades ao respectivo Poder Legislativo, sem estabelecer, de forma expressa e transparente, a obrigatoriedade de divulgação dos mesmos, o prazo para sua elaboração e apresentação, nem quais informações devem conter os referidos relatórios de atividades. A ausência de regras claras possibilita que existam relatórios que tenham o mesmo nome, sejam emitidos por órgãos que possuem as mesmas finalidades, porém estejam abordados de forma diversa, inclusive quanto à sua divulgação à sociedade.

Os órgãos públicos, ao levar em conta a sua responsabilidade social, devem divulgar informações sobre o seu comportamento e suas atividades (Galera et al., 2015), e ao fazê-lo não devem considerar somente o intuito de legitimar a sua existência, senão também de informar as partes interessadas como eles estão respondendo a suas demandas. No Manual de Transparência Fiscal, o Fundo Monetário Internacional - FMI - diz que o acesso rápido e gratuito publicado na Internet é um dos pilares da tempestividade e da uniformidade na disponibilização das informações fiscais (FMI, 2007).

Os Tribunais de Contas possuem uma relevância respeito à Governança Pública (IFAC, 2001; FMI, 2007), que pode ser observada, por exemplo, na sua função de analisar as contas públicas ou então ao exercer o papel de guardião da Lei de Responsabilidade Fiscal (Arantes et al., 2010). Sob tais circunstâncias, eles constituem um importante elemento da democracia e da cidadania (Filomena, 2012). Desta forma, além das competências institucionais pertinentes ao accountability horizontal, caberia aos Tribunais de Contas fomentarem as ações relativas aos princípios da integridade e da transparência. Integridade relacionada à probidade e à eficiência na administração dos recursos públicos e transparência referindo-se à ampla divulgação de informações de interesse da sociedade.

\section{ESTUDOS EMPÍRICOS SOBRE DIVULGAÇÃO NO SETOR PÚBLICO}

Embora a temática estudada seja recente, a revisão de literatura empírica possibilitou identificar um estudo de Copley, publicado em 1991, o qual analisou a relação entre a divulgação de governos municipais e a qualidade da auditoria. $\mathrm{O}$ autor argumenta que divulgações mais completas melhoram a reputação das auditorias independentes. Estas, para manter uma reputação de qualidade, influenciam positivamente no nível de divulgações. O resultado da sua pesquisa concluiu assim que há relação entre qualidade da auditoria e nível de divulgação de informações. 
Em período mais recente, revisando a literatura de incentivos para divulgação no setor público, foi encontrado o estudo de Bakar e Saleh (2011). Eles destacam que a partir de 2005 começaram a ser realizados estudos sobre incentivos de divulgação dos relatórios financeiros publicados na Internet, em adição aos tradicionais em papel. Os autores sugerem que esse tipo de pesquisa deve ser imitado por futuros pesquisadores, para o funcionamento harmonioso da contabilidade e tecnologia, de modo a alcançar maior transparência e prestação de contas. $\mathrm{O}$ estudo menciona, ainda que a maioria das pesquisas sobre divulgação foram sobre governos locais, incitando a realização de mais estudos sobre governos federais e estaduais.

Na esfera municipal Sánchez et al. (2013) realizaram uma análise de conteúdo sobre o grau de divulgação e o impacto de determinados fatores contextuais e políticos na transparência pública em 102 páginas eletrônicas de governos municipais da Espanha. Os resultados indicaram que a quantidade de informações divulgadas em matéria de informação social e ambiental era bastante escassa comparada com a quantidade de informações financeiras divulgadas. Além disto, afirmaram que a rivalidade política e os governos conservadores podem gerar verdadeiros obstáculos à transparência municipal.

Do mesmo modo, Martani et al. (2014) também realizam uma análise que avalia as divulgações não financeiras nas páginas eletrônicas de 434 municípios da Indonésia. Os resultados indicam que apenas 10\% dos municípios divulgaram informações sobre programas de desenvolvimento da comunidade, programas anticorrupção e questões ambientais. De outra parte, $50 \%$ divulgaram informações sobre a área geográfica, turismo e atratividade.

Já Galera et al. (2015) realizaram uma pesquisa que investiga as páginas eletrônicas de 21 municípios europeus de países nórdicos, e analisaram a evidenciação da informação relacionada com a reponsabilidade social de cada ente de governo. Eles afirmam que o grande número de serviços prestados pela administração local sugere um grande nível de divulgação por parte do ente público. Os resultados indicaram que os municípios noticiavam menos da metade do conteúdo recomendado pelas organizações internacionais, o qual era de caráter informativo e não seguia um padrão de coordenação, apresentando pouca acessibilidade aos dados.

Spamann e Naughton (2015), ao falar de divulgações e evidenciações no setor público, afirmam que as finanças de muitos estados e cidades encontram-se em apuros. Tal situação, segundo os pesquisadores, provém do regime desatualizado e ineficaz de informação financeira utilizada pelas entidades públicas. Os autores argumentam que a comunicação ineficaz obscurece os problemas financeiros municipais e prejudica a aplicação de ações corretivas.

Jacques et al. (2013) analisaram o nível de transparência dos municípios com mais de 100 mil habitantes no Estado do Rio Grande do Sul e observaram que população, PIB e receita arrecadada são variáveis que, se analisadas em conjunto, servem para definir grupos de municípios com situações similares em relação a transparência. $\mathrm{O}$ estudo analisa a preocupação dos munícipios em apresentar informações por meio de seus portais eletrônicos, concluindo com o destaque para a divulgação das ações de gestão de recursos coletivos e, por outro lado, o pouco destaque dado à disponibilização de ferramentas que possibilitem a participação do público no controle democrático.

Já Machado e Macagnan (2015) analisaram o nível geral de divulgação das administrações municipais com mais de 50 mil habitantes na região sul do Brasil. Os autores concluíram que o referido nível é baixo, visto que nenhum município evidenciou todos os 86 indicadores de informação testados, sendo que nem mesmo a informação obrigatória foi completamente evidenciada pelos municípios. Além disto, identificaram que municípios com melhores índices socioeconômicos e maior captação de recursos têm maior disposição de divulgar as informações, demonstrando a preocupação desses gestores em minimizar os efeitos da assimetria informacional e, assim, garantir a manutenção de sua legitimidade na sociedade.

A pesquisa de Franco et al., identificou o nível de transparência eletrônica dos municípios do Paraná. Seus resultados foram "que $81,25 \%$ dos municípios com 50.000 ou mais habitantes disponibilizaram os relatórios 
da Lei de Responsabilidade Fiscal em suas páginas eletrônicas e este índice cai para 29,43\% nos municípios com menos de 50.000 habitantes" (2014, p.140).

Lino e Aquino (2018) tiveram como objetivo analisar a diversidade da configuração interna dos Tribunais de Contas regionais, bem como a eventual associação deste aspecto com a qualidade da auditoria financeira. Com base nos resultados obtidos, os autores afirmam que muitas diferenças são respostas dos próprios órgãos às condições a que são expostos, tais como restrição de recursos, dispersão geográfica e número de jurisdicionados. Dentre as consequências desta não uniformidade de procedimentos, os autores destacam o eventual impacto no processo de convergência à contabilidade internacional e inclusive em relação às demonstrações consolidadas no Balanço do Setor Público Nacional. Referem, ainda, que a atuação dos Tribunais de Contas pode fortalecer os mecanismos de governança fiscal dos seus jurisdicionados.

Fernandes, Fernandes e Teixeira (2018) tratam os Tribunais de Contas como mecanismos de controle a partir da participação social que têm influência na efetividade da accountability horizontal. Concluem que tais órgãos são independentes entre si e possuem liberdade quanto ao exercício de suas atividades, o que possibilita a existência de regras distintas conforme cada realidade. Esta situação, segundo os autores, pode prejudicar o exercício de uma accountability horizontal mais efetiva. Discorrem também os autores da necessária publicidade e disseminação dos relatórios das auditorias para que "o controle horizontal seja efetivo nas diferentes unidades da Federação” (Fernandes, Fernandes e Teixeira, 2018, p. 145).

\section{METODOLOGIA}

Como já mencionado, a população desta pesquisa corresponde aos trinta e quatro Tribunais de Contas brasileiros existentes no encerramento do exercício de 2016, quais sejam: o Tribunal de Contas da União TCU-; os vinte e seis Tribunais de Contas dos Estados -TCE-; o Tribunal de Contas do Distrito Federal -TCDF-; dois Tribunais de Contas de Município e quatro Tribunais de Contas dos Municípios. Embora o Tribunal de Contas dos Municípios do Ceará -TCM-CE- tenha sido extinto em 2017, o mesmo foi analisado, pois o respectivo relatório de atividades estava disponibilizado na Internet no período da pesquisa. Do total de Tribunais de Contas brasileiros, nove deles não disponibilizaram os relatórios de atividades de 2016, em suas respectivas páginas eletrônicas. Restaram vinte e cinco com os quais foi desenvolvida a análise. Assim, em termos de análise de relatórios de atividades, a amostra representa $73,5 \%$ da população. Dentre os relatórios obtidos, vinte e dois são anuais, dois são trimestrais e um é bianual (2015/2016).

A coleta deste material foi realizada entre setembro/2017 e dezembro/2017, através de consultas nas páginas eletrônicas dos Tribunais de Contas brasileiros. A escolha pelo exercício de 2016 deve-se ao fato de que este é o último encerrado no momento da realização do estudo. Posteriormente foi procedida a análise dos vinte e cinco relatórios, observando os seguintes estágios de identificação das informações, que representam os conteúdos abordados em cada seção: 1) temas; 2) frequência dos mesmos; 3) assuntos correspondentes a cada um dos temas; 4) relação existente entre os diferentes temas.

Para identificar os temas abordados nos relatórios de atividades, foram selecionados os tópicos apresentados nas seções primárias de cada relatório de atividades. Tal escolha baseia-se na NBR 6024 da ABNT, que define a seção primária (por exemplo, seção 1, seção 2, seção 3) como a principal divisão do texto. Já a seguinte etapa, foi feita tabulando os dados de forma a identificar a frequência com que tais assuntos foram abordados pelos distintos Tribunais de Contas brasileiros. A seleção dos frequentes foi realizada considerando apenas os temas que constaram como seção primária em pelo menos dois relatórios distintos. Além disto, seções como "Introdução", “Considerações Iniciais", “Conclusão", "Considerações Finais” e "Anexos” foram desconsideradas, pois, habitualmente, estas tratam da apresentação e da síntese das situações descritas nos relatórios de atividades e não caracterizam temáticas diferentes daquelas abordadas nas outras seções. 
Em seguida foram analisadas as seções secundárias, as quais correspondem à divisão do texto de uma seção primária (ABNT, 2012), com a finalidade de identificar os conteúdos abordados em cada tema, a existência de relação entre os temas, bem como a diferenciação entre as abordagens dos distintos Tribunais de Contas. Os temas contemplados em seções subsequentes (terciárias e quaternárias, por exemplo) não foram considerados no estudo, podendo tal aspecto ser entendido como uma limitação deste trabalho.

\section{RESULTADOS DA ANÁLISE}

Dos trinta e quatro Tribunais de Contas brasileiros existentes no encerramento do exercício de 2016, apenas vinte e cinco divulgaram os respectivos relatórios de atividades na Internet até o final do exercício de 2017. Ou seja, 26,5\% dos relatórios de atividades não haviam sido divulgados nas páginas eletrônicas dos referidos órgãos um ano após o encerramento do exercício. Portanto, esses Tribunais de Contas deixaram de cumprir um aspecto essencial do sistema de governança pública, quanto à transparência (IFAC, $2001 \mathrm{e}$ ONU, 2007). Logo, os resultados indicam a existência de problemas de transparência e/ou de tempestividade no procedimento de divulgação da atuação de tais órgãos à sociedade, situação mencionada no Manual de Transparência Fiscal do FMI (2007), contrariando qualquer expectativa do cidadão, uma vez que se espera que os órgãos fiscalizadores do Estado sejam referência daquilo que fiscalizam. O exemplo é o comportamento mínimo esperado de quem pretende controlar e orientar demais órgãos do Estado.

A partir da análise dos vinte e cinco relatórios de atividades foram identificados vinte e um temas frequentemente abordados nas seções primárias, relacionados ou não entre si. Os resultados desta etapa estão relacionados na Tabela 3. Foi possível identificar que o tema relacionado ao Controle Externo, observado em vinte e um relatórios de atividades, é a única temática destacada em mais de $50 \%$ dos relatórios examinados. Além deste, os temas mais recorrentes dizem respeito às Atividades Administrativas e ao Relacionamento e Parcerias, aparecendo com destaque em onze relatórios de atividades, ou seja, $44 \%$ dos relatórios examinados. Por outra parte, entre os temas com menor número de abordagens destacam-se Consultoria e Assessoramento, tendo destaque em dois relatórios de atividade, Tecnologia da Informação, Recursos Humanos e Pessoas, Processos e Auditores Substitutos, com destaque em três relatórios de atividades cada. Os resultados indicam a ausência de padronização quanto às abordagens realizadas pelos Tribunais de Contas brasileiros em seus relatórios de atividades, bem como que temas relevantes não são apresentados em posição de destaque em tais relatórios. 
TABELA 3

Assuntos apresentados como itens nos sumários dos relatórios de atividades dos Tribunais de Contas brasileiros

\begin{tabular}{l|c}
\hline Temas / Assuntos & Frequência \\
\hline Controle Externo & 21 \\
Atividades Administrativas & 11 \\
Relacionamento e Parcerias & 11 \\
Sobre o TC & 9 \\
Ministério Público de Contas & 9 \\
Competência, Jurisdição e Estrutura & 8 \\
Plenário e Órgãos deliberativos & 8 \\
Resultados e Principais Realizações & 8 \\
Escola de Contas e Capacitação & 7 \\
Gestão, Planejamento e Estratégia & 6 \\
Ouvidoria & 6 \\
Gestão Orçamentária e Financeira & 6 \\
Desenvolvimento Institucional & 5 \\
Comunicação e Divulgação & 4 \\
Controle Interno & 4 \\
Corregedoria & 4 \\
Tecnologia da Informação & 3 \\
Recursos Humanos e Pessoas & 3 \\
Processos & 3 \\
Auditores Substitutos & 3 \\
Consultoria Técnica e Assessoramento & 2 \\
\hline
\end{tabular}

Dados da pesquisa

No que concerne ao tema "Controle Externo", o artigo 71 da Constituição Federal atribui aos Tribunais de Contas responsabilidade pelo exercício do controle externo da Administração Pública. Logo, pode-se inferir que a elevada frequência desta temática nos relatórios de atividades decorra do fato de tratar diretamente da atuação dos Tribunais de Contas brasileiros. Entretanto, a análise de conteúdo revela quão abrangente é este tema, tendo em vista a quantidade de assuntos contemplados, a saber: denúncias analisadas, medidas cautelares, atividades de fiscalização, processos julgados e as respectivas sessões de julgamentos, número de servidores, entre outros. Em diversas situações foi constatado que a abordagem sobre o "Controle Externo" contempla, também, como subitens, assuntos analisados em outros temas, tais como Atuação do Ministério Público de Contas; Comunicação das Decisões; Deliberações dos Colegiados; Jurisdição; Recursos Humanos e Pessoas. O resultado da análise demonstra que apesar do tema ser tratado em grande parte dos relatórios de atividades, o mesmo é abordado de forma diferente pelos diversos Tribunais de Contas brasileiros.

Na temática "Atividades Administrativas" são descritos aspectos relativos à gestão orçamentária, financeira, patrimonial, de licitações e contratos e de pessoal. Também é apresentado o assunto do planejamento e da modernização institucional, além de atividades de capacitação realizadas pelo respectivo órgão. Os tópicos abordados nesse item são amplos, sendo que muitos foram tratados como itens próprios em outros relatórios, como, por exemplo, Escola de Contas e Capacitação, Planejamento, Gestão Orçamentária e Financeira e Recursos Humanos e Pessoas.

Já o tema "Relacionamento e Parcerias" contempla a interação dos Tribunais de Contas com o ambiente em que os mesmos estão situados, aspectos relativos à forma como ocorre o relacionamento do Tribunal de Contas com a Sociedade, com os Poderes e com os jurisdicionados. Além disto, faz referência aos projetos existentes, convênios e acordos de fiscalização estabelecidos junto a outros órgãos públicos. Nesta temática são abordados, ainda, assuntos como Comunicação e Ouvidoria, os quais constam em outros relatórios como seção principal.

O tema denominado "Sobre o TC" trata da competência e da jurisdição do órgão, abordadas em outros relatórios como seção primária. Além disto, a temática contempla a composição, a estrutura e o organograma 
do respectivo Tribunal de Contas. Aspectos relacionados à legislação e às relações institucionais também são abordados.

Em relação ao tema "Ministério Público de Contas", refere-se à atuação do órgão, sendo apresentadas informações sobre a instituição, as atividades desenvolvidas no período e as ações em destaque. Também o número de processos examinados pelo MPC, bem como aqueles já julgados pelo Tribunal de Contas.

Sobre atividades do "Plenário e Órgãos Deliberativos" as informações dizem respeito à atuação dos Conselheiros dos Tribunais de Contas, seja em relação ao número de processos julgados, às deliberações dos órgãos colegiados, às sessões realizadas, ou então, às atividades da presidência. Em alguns casos foram apresentados os montantes relativos à determinação de ressarcimento ao Erário, ou então, quanto à imposição de penalidade pecuniária aos gestores.

Por outro lado, "Resultados e Principais Realizações" trata das ações do controle externo e dos órgãos julgadores; ademais, assuntos relacionados ao aperfeiçoamento da gestão e da governança pública, da efetividade das ações do controle externo, da transparência e do controle social, além de temas como fiscalização, composição e consultas.

A informação apresentada em "Gestão, Planejamento e Estratégia” abrange os processos de gestão do planejamento estratégico, projetos, processos e orçamento. Além disso, tal tema contempla aspectos como liderança, sustentabilidade, acessibilidade e alguns tópicos contemplados em destaque na seção principal em outros relatórios, tais como: "Recursos Humanos e Pessoas", "Corregedoria", "Tecnologia da Informação", "Controle Interno", "Comunicação e Divulgação” ou "Gestão Orçamentária e Financeira”.

Por fim, os temas: "Competência, Jurisdição e Estrutura", "Ouvidoria” e "Escolas de Contas e Capacitação" não contemplam subitens, ou então, os subitens tratam de assuntos que denominam a seção. A análise realizada evidenciou que temas como "Desenvolvimento Institucional", "Comunicação e Divulgação", "Controle Interno", “Tecnologia da Informação", "Recursos Humanos e Pessoas” constaram como seção primária em menos de $20 \%$ do total de relatórios de atividades analisados. No entanto, estes mesmos temas são apresentados em seções secundárias em outros relatórios de atividades. Ou seja, embora tratem de temas relevantes na atuação dos órgãos em questão, esses assuntos não assumem posição de destaque nos relatórios apresentados ao Poder Legislativo.

Os últimos estágios de identificação das informações nesta pesquisa demonstram que assuntos ora são apresentados nas seções primárias, ora aparecem em seções secundárias. A análise de conteúdo dos relatórios em conjunto evidencia a ausência de padrão dos Tribunais de Contas em relação aos temas a serem apresentados ou à própria abordagem dos mesmos. Tal situação é coerente com as conclusões de Fernandes, Fernandes e Teixeira (2018) no que se refere a que a liberdade para o exercício das atividades dos Tribunais de Contas e a existência de regras distintas entre estes órgãos seriam prejudiciais à efetividade da accountability horizontal. É relevante destacar que a accountability horizontal é uma resposabilidade atribuída aos Tribunais de Contas (Arantes et al., 2010), o que indica a necessidade de aprimoramento quanto à situação descrita.

\section{CONSIDERAÇÕES FINAIS}

Esta pesquisa analisou o grau de transparência dos Tribunais de Contas brasileiros, considerando a disponibilidade dos seus relatórios de atividades nas respectivas páginas eletrônicas na Internet e seu conteúdo. Os Tribunais de Contas são responsáveis pelo controle financeiro externo da Administração Pública e têm a responsabilidade de fiscalizar auditando o cumprimento das exigências da Lei de Responsabilidade Fiscal e da transparência (Brasil, 2000; Brasil, 2009). Neste sentido, seria esperado que tais órgãos adotassem postura e conduta exemplares em relação à divulgação das suas atuações.

No entanto, órgãos de controle externo podem estar sujeitos a problemas de tempestividade e de uniformidade na disponibilização das informações (FMI, 2007). No caso em questão, isto ocorre porque a 
legislação vigente exige a apresentação de relatórios das atividades ao respectivo Poder Legislativo, porém não estabelece o período para a sua elaboração e apresentação e não estabelece a padronização das informações que devem ser apresentadas nos referidos relatórios de atividades.

O principal resultado desta pesquisa foi que os Tribunais de Contas brasileiros apresentam comportamento de transparência e de accountability não exemplar, o que se traduz em deficiência de Governança Publica, uma vez que a análise realizada indica que 26,5\% dos relatórios de atividades relativos ao exercício de 2016 não haviam sido divulgados nas páginas eletrônicas dos referidos órgãos até o final de 2017 na Internet. Isto permite pensar que esses Tribunais de Contas, organismos de auditoria e fiscalização do Estado, não entendem que seu comportamento mereça ser conhecido ou transparente, ou seja, que estão acima de análise e avaliação da sociedade. Porém, no sistema de Governança Pública, espera-se que um órgão fiscalizador ou mesmo de auditoria adote um comportamento que fortaleça o crédito de suas atividades. A falta de transparência dos tribunais de contas não contribui para a confiança da sociedade nestes organismos do Estado.

Os Tribunais de Contas poderiam argumentar que essa atividade remeteria a custos e por esta razão seria evitada. Todavia, uma vez que os custos de sistematização e de publicação estão cada dia mais acessíveis, esse argumento que não se sustenta, seja pelo avanço tecnológico da área de comunicação e informática ou porque as informações a serem publicadas devem ser sistematizadas internamente no sentido de apoio ao sistema gerencial do respectivo Tribunal de Contas. Assim, é um custo já suportado pela necessidade dos gestores ou pela possibilidade tecnológica que não oferece acréscimos de gastos significativos a serem estabelecidos.

A análise dos relatórios disponibilizados evidenciou a ausência de padronização nas informações. Portanto, é inviável a comparabilidade entre as informações apresentadas pelas instituições de controle externo. Sendo assim, tais aspectos indicam também a existência de problemas de transparência e/ou de tempestividade no procedimento de divulgação dos relatórios de atividades à sociedade, situação mencionada no Manual de Transparência Fiscal do FMI (2007). Ademais, prejudicam a efetividade da accountability horizontal, a qual é de competência dos Tribunais de Contas (Fernandes, Fernandes e Teixeira, 2018).

As evidências encontradas guardam relação com os resultados apresentados por Sánchez et al. (2013) e Martani et al. (2014). Ambos analisaram o grau de divulgação nos websites dos governos municipais da Espanha e Indonésia, respectivamente, sendo que os dois depararam-se com o mesmo problema de comparabilidade e nível semelhante de transparência. Ao final, eles ressaltam a necessidade de estabelecer políticas que gerem níveis semelhantes de transparência e divulgação entre governos. Esta recomendação também é aplicável ao presente estudo, ou seja, em relação aos Tribunais de Contas revela-se necessário o estabelecimento de critérios claros e objetivos na transparência de tais órgãos, especialmente quanto à atuação institucional de controle externo à Administração Pública.

Por outra parte, os resultados ora encontrados diferem daqueles obtidos por Copley (1991) considerando as atribuições dos Tribunais de Contas de fiscalização em referência ao cumprimento da Lei de Transparência (Brasil, 2009). O citado autor indica uma relação proporcional entre a qualidade da auditoria e o nível de divulgação de informações. E, neste aspecto, deve-se destacar a importância da transparência para a Governança Pública, pois a mesma possibilita que a sociedade tenha conhecimento sobre os serviços a serem prestados pela Administração Pública e possa exigir que os mesmos sejam realizados de forma eficiente (ONU, 2007).

Ainda neste contexto, os resultados demonstram, tendo em vista as delimitações definidas para a presente pesquisa, que os Tribunais de Contas brasileiros, em seu conjunto, não cumprem adequadamente o papel de informar sobre as atividades desenvolvidas. Logo, falham em relação à responsabilidade social que possuem em termos da divulgação de informações que atendam às demandas da sociedade, conforme Galera et al. (2015). A forma de atuação dos Tribunais de Contas, tanto nas auditorias quanto nas suas ações administrativas, não só pode atender essas demandas, mas direcionar os seus jurisdicionados à melhoria dos níveis de governança (Lino e Aquino, 2018). 
Apesar dos resultados obtidos, é relevante destacar que o Tribunal de Contas da União, mediante Decisão Normativa TCU 170/2018, passou a adotar nos seus relatórios de auditoria o modelo do relato integrado, desenvolvido pelo International Integrated Reporting Council. Este modelo tem o objetivo de integrar informação financeira e não financeira de forma concisa e abrangente, contemplando a estratégia, a governança, o desempenho e as perspectivas das organizações. Além do aumento da eficiência, a medida visa tornar os relatórios mais transparentes e de fácil compreensão para as partes interessadas (TCU, 2018).

Regulamentação semelhante poderá trazer benefícios aos relatórios de atividades objetos deste estudo, contribuindo para a melhoria na efetividade da accountability horizontal. Benefícios que, ao padronizar, viabilizam a comparabilidade das informações apresentadas. Cabe destacar, neste panorama, que organizações como a Associação dos Membros dos Tribunais de Contas do Brasil -Atricon- e Instituto Rui Barbosa IRB- podem contribuir para a diminuição da heterogeneidade dos Tribunais de Contas (Lino e Aquino, 2018).

Entende-se relevante para novas pesquisas o desenvolvimento da análise das informações divulgadas nos relatórios de atividades dos Tribunais de Contas brasileiros. Por um lado, estas poderão analisar outras formas de divulgação das informações relativas às atividades desempenhadas pelos Tribunais de Contas brasileiros, como publicações em jornais e/ou revistas, entre outras, com a finalidade de aprimorar o entendimento sobre o nível de transparência dos Tribunais de Contas brasileiros. Igualmente, poderão ampliar a análise no sentido de identificar a evolução no tempo da transparência, considerando o desenvolvimento de uma amostra com mais anos. Esta última, podendo evidenciar diferenças na organização, na estrutura funcional e nos próprios procedimentos realizados. Caberia também, o desenvolvimento de estudos que possibilitassem identificar as informações que a sociedade teria como objetivo conhecer, pois, transparência não significa só divulgar, mas sim possibilitar acesso às informações de real interesse e utilidade para a sociedade.

\section{Referências}

ACRE. (1989). Constituição do Estado do Acre. Disponível em: www.al.ac.leg.br/wp-content/uploads/2014/10/ constituição_atualizada.pdf. Acesso em: 20/09/2017.

Arantes, R. B., Loureiro, M. R., Couto, C., \& Teixeira, M. A. (2010). Controles democráticos sobre a administração pública no Brasil: Legislativo, Tribunais de Contas, Judiciário e Ministério Público. Em Loureiro et al. Burocracia e política no Brasil. Desafios para o Estado democrático no século XXI. (v. 26). Rio de Janeiro: FGV.

Associação Brasileira de Normas Técnicas - ABNT. (2012). ABNT NBR 6024 Informação e documentação, Numeração progressiva das seções de um documento. Rio de Janeiro.

Bahia. (1989). Constituição do Estado da Bahia. Disponível em: www.legislabahia.ba.gov.br/verdoc.php?id=73273. Acesso em: 20/09/2017.

Bakar, N. B., \& Saleh, Z. (2011). Incentives for disclosure of accounting information in public sector: a literature survey. International Research Journal of Finance and Economics, 75(1), 24-38.

Brasil. (1988). Constituição da República Federativa do Brasil de 1988. Disponível em: www.planalto.gov.br/ ccivil_03/Constituicao/Constituicao.htm. Acesso em: 20/09/2017.

Brasil. (2000). Lei Complementar 101, de 04 de maio de 2000. Estabelece normas de finanças públicas voltadas para a responsabilidade na gestão fiscal e dá outras providências. Disponível em: www.planalto.gov.br/ccivil_03/Leis/ LCP/Lcp101.htm. Acesso em: 20/09/2017.

Brasil. (2009). Lei Complementar 131, de 27 de maio de 2009. Acrescenta dispositivos à Lei Complementar no 101, de 4 de maio de 2000, a fim de determinar a disponibilização, em tempo real, de informações pormenorizadas sobre a execução orçamentária e financeira da União, dos Estados, do Distrito Federal e dos Municípios. Disponível em: www.planalto.gov.br/ccivil_03/leis/LCP/Lcp131.htm. Acesso em: 20/09/2017.

Brasil. (2011). Lei Federal 12.527, de 18 de novembro de 2011. Regula o acesso a informaçóes previsto no inciso XXXIII do art. 5, no inciso II do $\$ 3$ do art. 37 e no $\$ 2$ do art. 216 da Constituição Federal; altera a Lei 8.112, de 
11 de dezembro de 1990; revoga a Lei 11.111, de 5 de maio de 2005, e dispositivos da Lei 8.159, de 8 de janeiro de 1991; e dá outras providências. Disponível em: http://www.planalto.gov.br/ccivil_03/_ato2011-2014/2011/ lei/112527.htm. Acesso em: 20/09/2017.

Brasil. (2017). Decreto 9.203, de 22 de novembro de 2017. Dispõe sobre a política de governança da administração pública federal direta, autárquica e fundacional. Disponível em: http://www.planalto.gov.br/ccivil_03/ _ato2015-2018/2017/decreto/D9203.htm. Acesso em: 27/01/2019.

Copley, P. A. (1991). The association between municipal disclosure practices and audit quality. Journal of Accounting and Public Policy, 10(4), 245-266. DOI: https://doi.org/10.1016/0278-4254(91)90001-Z

Fernandes, G. A. L., Fernandes, I. L. A., \& Teixeira, M. C. (2018). Estrutura de funcionamento e mecanismos de interação social nos tribunais de contas estaduais. Revista do Serviço Público, 69, 123-150. DOI: https:// doi.org/10.21874/rsp.v69i0.3585

Filomena, C. L. (2012). Democracia, políticas públicas e controle. Em M. Oliveira de, \& S. T. Bergue (Orgs.), Políticas públicas: definiçôes, interlocuções e experiências (pp. 165-183). Recurso eletrônico. Caxias do Sul/RS. Educs.

Franco, L. M. G., Rezende, D. A., Figueiredo, F. de C., \& Nascimento, C. (2014). Nível de divulgação eletrônica da contabilidade pública dos municípios do Paraná no Ambiente da Internet. Revista de Ciências da Administração, 16(38), 140-153. DOI: https://doi.org/10.5007/2175-8077.2014v16n38p140

Fundo Monetário Internacional - FMI. (2007). Manual de Transparência Fiscal. Disponível em: https://www.imf.org/ external/np/fad/trans/por/manualp.pdf. Acesso em 20/09/2017.

Galera, A., Valencia, P. T., Lozano, M. R., \& Berjillos, A. L. (2015). Divulgación de información sobre responsabilidad social de los gobiernos locales europeos: El caso de los países nórdicos. Gestión y política pública, 24(1), 229-270. DOI: http://dx.doi.org/10.29265/gypp.v24i1.100

Goiás. (1989). Constituição do Estado de Goiás. Disponível em: www.gabinetecivil.goias.gov.br/constituicoes/ constituicao_1988.htm. Acesso em: 20 de setembro de 2017.

International Federation of Accountants - IFAC. (2001). Governance in the public sector: A governing body perspective. Study 13. Disponível em: https://www.ifac.org/publications-resources/study-13-governancepublic-sector. Acesso em 20 de setembro de 2017.

Jacques, F. V. S., Quintana, A. C., \& Macagnan, C. B. (2013). Transparência em municípios da região sul do Brasil. Em XXXVII Encontro da ANPAD. Rio de Janeiro. Anais eletrônicos.

Kooiman, J. (1999). Social-political governance: Overview, reflections and design. Public Management: An International.Journal of Research and Theory, 1(1), 67-92. DOI: https://doi.org/10.1080/14719037800000005

Lino, A. F., \& Aquino, A. C. B. de. (2018). A diversidade dos Tribunais de Contas regionais na auditoria de governos. Revista Contabilidade \& Finanças, 29(76), 26-40. DOI: 10.1590/1808-057x201803640

Machado, V. N., \& Macagnan, C. B. (2015). Public governance: Factors of disclosure from the Municipalities of southern Brazil. Journal of Public Administration and Governance, 5(4), 1-22. DOI: 10.5296/ jpag.v5i4.8409.

Martani, D., Nastiti, D., \& Wicaksono, P. T. (2014). Disclosure of non-financial information about public services on the official website of local governments in Indonesia. Journal of Theoretical \& Applied Information Technology, 66(1), 500-512.

Melo, M. A., Pereira, C., \& Figueiredo, C. M. (2009). Political and institutional checks on corruption: Explaining the performance of Brazilian audit institutions. Comparative Political Studies, 42(9), 1217-1244. DOI: https:// doi.org/10.1177/0010414009331732

O’Donnell, G. (1998). Horizontal Accountability in New Democracies. Journal of Democracy, 9(3), 112-126. DOI:10.1353/jod.1998.0051

Organização das Nações Unidas - ONU. (2007). Public Governance Indicators: A Literature Review. New York: ST/ ESA/PAD/SER.E/100, ONU.

Osborne, S. P. (2006). The New Public Governance? Public Management Review, 8(3), 377-387. DOI: https:// doi.org/10.1080/14719030600853022 
Peters, B. G., \& Pierre, J. (1998). Governance Without Government? Rethinking Public Administration. Journal of Public Administration Research and Theory - J-PART, 8(2), 223-243. DOI: https://doi.org/10.1093/ oxfordjournals.jpart.a024379

Sánchez, I. M. G., Aceituno, J. V. F., \& Domínguez, L. R. (2013). Determinants of corporate social disclosure in Spanish local governments. Journal of Cleaner Production, 39, 60-72. DOI: https://doi.org/10.1016/ j.jclepro.2012.08.037

Santa Catarina. (1989). Constituição do Estado de Santa Catarina. Disponível em: http://leis.alesc.sc.gov.br/html/ constituicao_estadual_1989.html. Acesso em: 20/09/2017.

São Paulo. (1989). Constituição do Estado de São Paulo. Disponível em: www.al.sp.gov.br/repositorio/legislacao/ constituicao/1989/compilacao-constituicao-0-05.10. 1989.html. Acesso em: 20/09/2017.

Simões, E. (2014). Tribunais de contas - Controle Externo das Contas Públicas. São Paulo, Editora Saraiva.

Spamann, H., \& Naughton, J. (2015). Fixing public sector finances: The accounting and reporting lever. UCLA. Law Review, 62, 572.

Speck, B. W. (2000). Inovação e rotina no Tribunal de Contas da União: o papel da instituição superior de controle financeiro no sistema político-administrativo do Brasil. São Paulo, Konrad Adenauer Stiftung.

Tribunal de Contas da União - TCU. (2018). Relatório de Gestão na forma de Relato Integrado. Disponível em: https://portal.tcu.gov.br/biblioteca-digital/orientacoes-para-elaboracao-dorelatorio-de-gestao.htm. Acesso em 27/01/2019.

\section{Notas}

* $\quad$ Artigo de pesquisa científica.

[1] Extinção decorrente da Emenda Constitucional no 92, de 16-08-2017, promulgada pela Assembleia Legislativa do referido Estado, sendo mantida pelo julgamento da Ação Direta de Inconstitucionalidade - ADI 5763 pelo Supremo Tribunal Federal, cuja decisão foi publicada em 10-11-2017.

Licencia Creative Commons CC BY 4.0 